\title{
Bacterial Lignin Peroxidase Mediated Biobleaching and Biodegradation of Paper and Pulp Mill Effluent
}

\author{
Priyanka Uttamrao Jadhav*¹, Bholay A. D. ${ }^{2}$, Mahesh Shindikar ${ }^{3}$, \\ Amruta Uttamrao Jadhav ${ }^{2}$ \\ ${ }^{1}$ Environmental Science Research Centre, K.T.H.M. College,Nasik, S.P.Pune University,MS,India \\ ${ }^{2}$ P.G. Dept. of Microbiology, K.T.H.M College, Nashik, S.P.Pune University,MS,India \\ ${ }^{3}$ Department of Applied Science, College of Engineering, Pune, MS, India \\ e-mail*_enjoypiyu@gmail.com
}

\begin{abstract}
Large amount of lingo-cellulosic waste generated by forestry, agricultural practices, paper-pulp industries and textile dye-stuff industries poses a severe environmental pollution problem. Paper factory effluent is one of the major pollutants on the earth because it is highly coloured. The persistent dark brown colour is due to dissolved lignin based synthetic, aromatic and chlorinated compounds derived from the blow heat condensate, pulp decker washing, chlorine and alkali bleach waste, black liquor spillage and foul evaporator condensate. Selection of correct and ecofriendly treatment method for paper-pulp mill waste-water prior to discharge into the environment is still a matter of concern. In the present study, the application of the lignin peroxidase enzyme as crude extracts of the bacterial isolate cultures was reported as an effective tool in biobleaching and biodegradation of paper pulp mill effluent which was measured spectrophotometrically. The isolates Sphingomonas paucimobilis and Corynebactrium jeikeium were found to be an efficient biobleaching agent as compared to the other isolates studied. They showed $91.32 \%, 86.57 \%, 84.21 \%$ and $83.82 \%, 82.43 \%$ and 78.94\% biobleaching respectively when applied as axenic cultures while the mixed consortia being the most effective showed the biobleaching in the range of $91.61 \%, 89.47 \%$ and $86.84 \%$ of the effluent $50 \%, 75 \%$ and $100 \%$ respectively.
\end{abstract}

Keywords: Lignin Peroxidase, Corynrbacterium jeikeium, Sphingomonas paucimobilis, Biobleaching.

\section{Introduction}

Large amounts of lingocellulosic waste are generated through forestry, agricultural practices, timber industries, textile due-stuff industries and mainly due to paper-pulp industries. These wastes contain compounds which are non-degradable by conventional treatment methods and pose severe environmental pollution problem [1]. The un-aesthetic persistent dark brown or black colour in the released paper and pulp industrial effluent is due to dissolved lignin based synthetic, aromatic and chlorinated compounds derived from the blow heat condensate, pulp decker washing, chlorine and alkali bleach waste, black liquor spillage and foul evaporator condensate. Lignin and its derivatives are difficult to degrade because of the linkages within the molecule especially the biphenyl type carbon-to-carbon linkages [2]. Chemical recovery is not carried out in small paper mills due to economic reasons [3]. The brown color of the effluent may increase water temperature and decrease photosynthesis which may lead to decreased concentration of dissolved oxygen. The growing awareness regarding environmental issues and their potential health hazards caused by polluted industrial waste water has prompted many countries to impose certain limits on the discharge of improperly treated or untreated effluents.

Lignin biodegradation is responsible for much of the natural destruction of wood in use, and it may have an important role in plant pathogenesis. On the other hand, potential applications utilizing lignin degrading organisms and their enzymes have become attractive, because they may provide environmental friendly technologies for the paper pulp and various other industries [4]. Lignin is an insoluble polymer; therefore, the initial steps in its biodegradation are extracellular. Due to its hydrophobicity and complex random structure that lacked the regular hydrolysable bonds, lignin is poorly degraded by most of the microorganisms. The organism known to extensively degrade lignin is fungi and to a lesser extent, certain actinomycetes and bacteria [5].

Paper-pulp mill industries as well as textile dye based industries release effluents having characteristic dark colour. In case of paper pulp effluent the color is due to lignin while for textile dye- based effluent it is due to various dyes mainly of azo group or mixture of dyes [6]. Both lignin and azo group dyes have a complex structure and are considered as recalcitrant compounds [7]. These effluents are discharged in natural water bodies causing water pollution due to their intense undesirable color. Conventional treatment methods like aerated lagoons and activated sludge plants are not much effective in removing the colour.

Many bacteria can produce extra-cellular peroxidase enzymes like Lignin peroxidase and Manganese Peroxidase etc. if they are supplemented with specific substrate. Lignin peroxidase enzyme belongs to the 
oxidoreductases group which can oxidize large number of complex structure as it is non-specific in action and acts on a wide range of substrates. It can bring about oxidative breakdown of many azo dyes like Brilliant Green, Congo Red, Remazol Brilliant Blue R, Poly R- 478, Reactive Red, and Golden Yellow [8]. Thus, Lignin peroxidase enzyme system can be applied for biobleaching of these colored effluents.

The present study focuses on biobleaching and biodegradation of paper pulp mill effluent by bacterial isolates applied as axenic cultures as well as in mixed consortium.

\section{Materials And Methods \\ 2.1 Enrichment, isolation and acclimatization of the lignolytic bacteria}

Enrichment and isolation of lignolytic bacteria were done by using various sample sources like rhizosphere soil with cow dung, lake water containing decomposing plant material, compost feedstock, decaying bark sample- scraps of decaying bark with crushed termites and Industrial effluent. The soil extract used for enrichment, isolation and acclimatization of the lignin degrading bacteria contained g/L, soil (40), D/W (960), settled for 1 hour. Clear supernatant (extract) was collected, autoclaved and stored in sterile bottle for further study. $1 \%$ Lignin soil extract agar medium containing (ml/100ml): soil extract (99); lignin (1); $\mathrm{H}_{2} \mathrm{O}_{2}(0.1 \mathrm{mM})$, antifungal- Fungdid B and agar agar, $(2.5 \mathrm{~g})$ was prepared, $\mathrm{pH}$ adjusted to 7, autoclaved at $15 \mathrm{lbs}$ for $15 \mathrm{~min}$. Similarly, for acclimatization of the isolates, $2.5 \%, 5 \%$ and $10 \% \mathrm{v} / \mathrm{v}$ soil extract lignin agar media were prepared using $2.5 \mathrm{ml}, 5 \mathrm{ml}$ and $10 \mathrm{ml}$ crude lignin in $97.5 \mathrm{ml}, 95 \mathrm{ml}$ and $90 \mathrm{ml}$ soil extract. All the other components of the media remained same.

The five enriched samples were poured on lignin agar medium. The plates were incubated at $30^{\circ} \mathrm{C}$ for 4-5 days. Each plate was examined for number of isolates and single isolated colonies were sub-cultured to obtain pure culture of selected isolate. All the isolates were then inoculated in $100 \mathrm{ml}$ of $1 \%$ lignin broth separately to check the decolourization of lignin. All the flasks were incubated at $30^{\circ} \mathrm{C}, 120 \mathrm{rpm}$ for $3-4$ days in a shaker incubator and checked for biobleaching visibly by comparing with un-inoculated control. The isolates were acclimatized at higher concentration of lignin to enhance their lignolytic activity on the same media with increasing concentration of crude lignin like $1 \%, 2.5 \%, 5 \%$ and $10 \% \mathrm{v} / \mathrm{v}$ and checked for qualitative lignolysis.

\subsection{Characterisation and identification of potent isolates}

Potent isolates White and Orange showing positive lignolytic activity were identified by using morphological and biochemical characterization methods at lab scale and using recent tools like API system (Vitek2, Version 6.01).

\subsection{Biobleaching and biodegradation of paper and pulp mill effluent}

Paper-pulp mill effluent was obtained from industrial area of Kolhapur and termed as Black Liquor. The textile dye based effluent was dark reddish brown in colour due to the presence of dyes. Synthetic Lignin was obtained from Sigma Aldrich. Minimal Broth containing 0.1\% w/v synthetic lignin was used for cultivation of isolates and biobleaching studies. Biobleaching of Paper and pulp mill effluent was studied at different concentrations of the effluent like 50\%,75\% and $100 \%$ with minimal broth as a diluent for each of the isolates. Different dilutions of the effluents were prepared, autoclaved and divided into three sets of six flasks i.e., $50 \mathrm{ml}$ effluent dilution for each isolate for each dilution. Antifungal was added to each flask to avoid fungal contamination. Each isolate was inoculated separately in the sterile $50 \mathrm{ml}$ effluent sample as axenic culture along with uninoculated control and mixed consortium and the rate of decolorization were monitored. $5 \mathrm{ml}$ samples were withdrawn aseptically at the intervals of $24 \mathrm{hrs}$, centrifuged at $7000 \mathrm{rpm}$ at $4^{0} \mathrm{C}$ and absorbance of the culture supernatant for each of the isolates for each effluent dilution were measured at $280 \mathrm{~nm}$ on U.V - Vis. Spectrophotometer U-2900. The activity (\% Biobleaching) was calculated using the formula after measuring the absorbance of the respective centrifuged effluents samples for consecutive 5 days. The percentage color reduction was measured as $\left(\mathrm{A}_{280}\right.$ on 1 st day $-\mathrm{A}_{280}$ on 5th day/ $\mathrm{A}_{280}$ on 1st day) x 100 [9]. Absorbance of the control was used as a reference point for calculations and expressed as \% biobleaching and biodegradation of the effluent.

\subsection{Lignin Peroxidase Enzyme (LiP) Assay}

Assay solution containing (ml): $50 \mathrm{mM}$ Sodium Potassium Tartarate (pH-4) buffer (1), $0.1 \mathrm{mM} \mathrm{H}_{2} \mathrm{O}_{2}$ inducer (0.1), $32 \mu \mathrm{M}$ methylene blue substrate (1) and enzyme solution (1). The spectrophotometric assay method for the determination of lignin peroxidase activity is based on the demethylation of the methylene blue dye. The method can be efficiently used for the quantification as its sensitivity is close to the veratryl alcohol assay. Methylene blue is used as a substrate and the enzyme lignin peroxidase demethylates methylene blue in the presence of $\mathrm{H}_{2} \mathrm{O}_{2}$ (inducer). The final product is a tri-demethylated methylene blue derivative, Azure $\mathrm{C}$ and the reaction occurs at $\mathrm{pH}-7$. Methylene blue demethylates to Azure C (leuco). Enzyme activity was measured as percent decolourization of the methylene blue dye. 
All the isolates were freshly inoculated in $50 \mathrm{ml}$ of $0.1 \% \mathrm{w} / \mathrm{v}$ synthetic lignin broth separately and as mixed consortium and incubated at $37^{\circ} \mathrm{C}$ at $120 \mathrm{rpm}$ for $48 \mathrm{hrs}$ in a shaker incubator to obtain a heavy bacterial growth. About $10 \mathrm{ml}$ of the culture broth of the isolates were taken in cooling centrifuge tubes and the culture broths were centrifuge at $4^{0} \mathrm{C}$ at $7000 \mathrm{rpm}$ in centrifuge. After centrifugation the tubes were kept in ice bath without disturbing it and enzyme assay was carried out using the supernatant. Assay solution was incubated at ambient temperature and $\mathrm{A}_{650}$ was measured. The results were interpreted as the percent decolourization of the methylene blue dye by the enzyme as compared to the control tube calculated as ( $\mathrm{Ab}{ }_{650}$ for control - Abs ${ }_{650}$ for test / Abs 650 for control) x 100.

\section{Results And Discussion}

\subsection{Enrichment, isolation and acclimatization of the lignolytic bacteria}

After enrichment and sub-culturing of the lignolytic bacteria, pure cultures were obtained on lignin agar plates (Fig.1). Some of the isolates were acclimatized on higher concentration of lignin and termed as potent isolates.
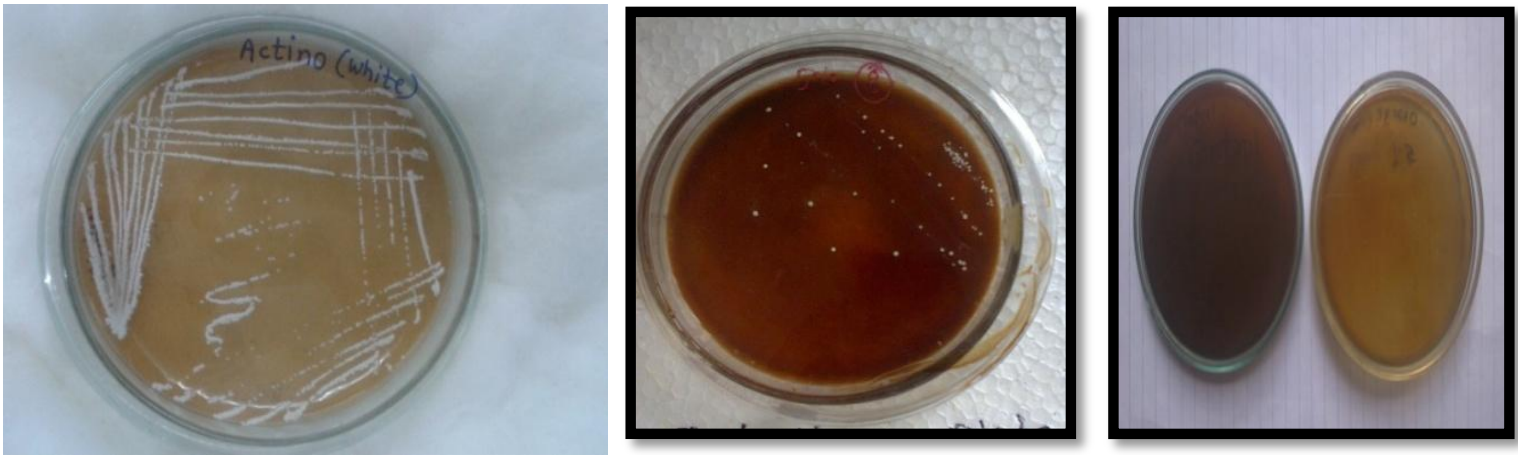

Fig.1 Growth of bacteria on lignin-agar medium and lignin decolorization

Total 16 isolates were obtained from various sample sources shown in Table 1 and their lignolytic activity was confirmed by decolorization of lignin agar plates shown in Fig.1.

Table 1. Isolates and their sample sources

\begin{tabular}{|l|l|}
\hline Source & Isolates \\
\hline Lake water & L1,L2,L3,L4,L5 and White \\
Rhizosphere soil with cow dung & C1,C2,C3,Red and Orange \\
Bark sample with termites & T1,T2,T3,T4 and 11(Actino). \\
\hline
\end{tabular}

\subsection{Characterization of Potent Isolates}

The two potent lignin degrading bacterial isolates White and Orange obtained based on the lignolytic activity were characterized and identified as Sphingomonas paucimobilis (White) and Corynebactrium jeikeium (Orange) by Vitek 2 system, version 06.01 shown in Table 2 and Table 3.

Table 2. Identification Report of the Isolate 'White' by Bactest Lab,Vitek 2 System

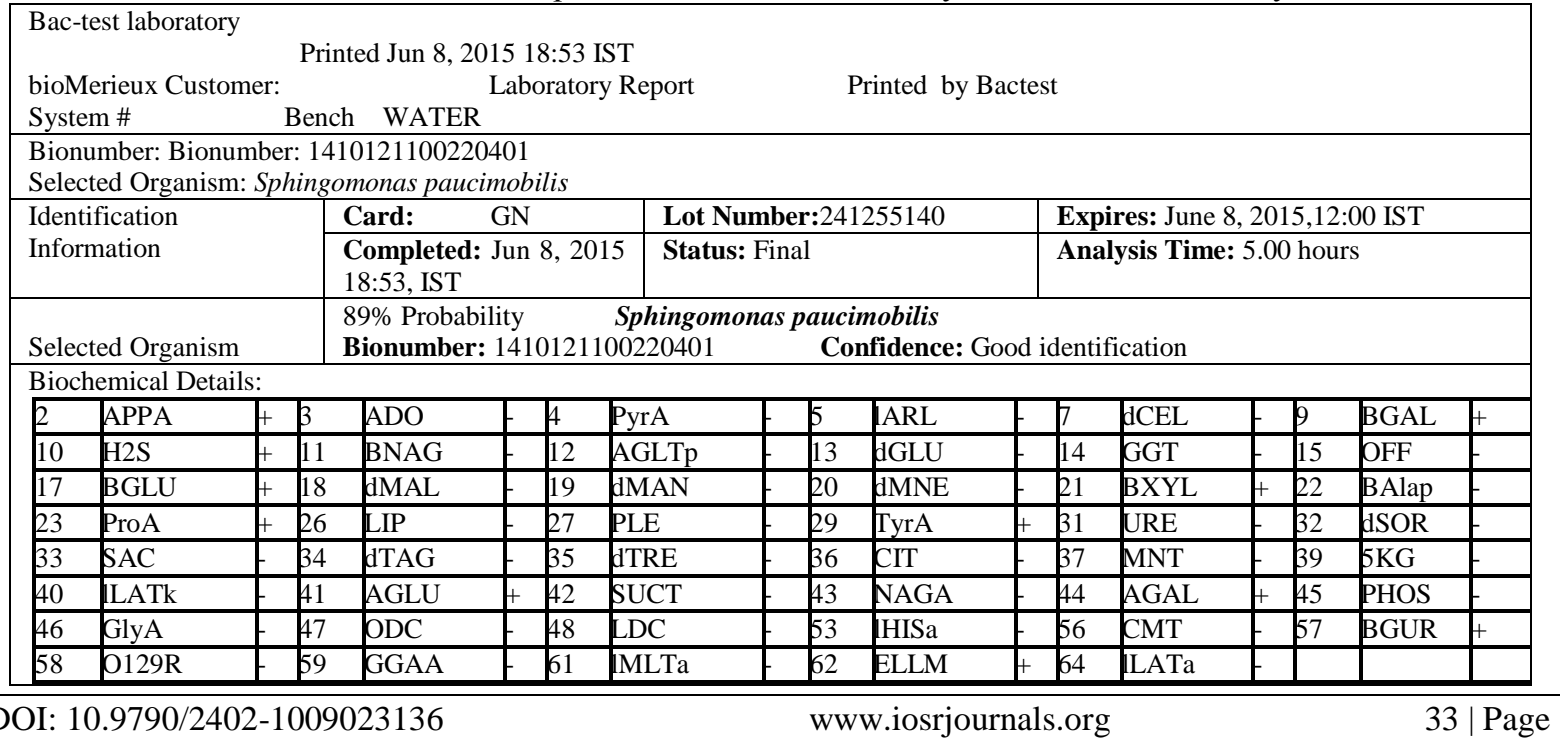


Bacterial Lignin Peroxidase Mediated Biobleaching And Biodegradation Of Paper And Pulp...

Installed VITEK 2 Systems Version: 06.01

MIC Interpretation Guideline:
Therapeutic Interpretation Guideline: AES Parameter Last Modified:

Table 3. Identification Report of the Isolate 'Orange' by Bactest Lab, Vitek 2 System

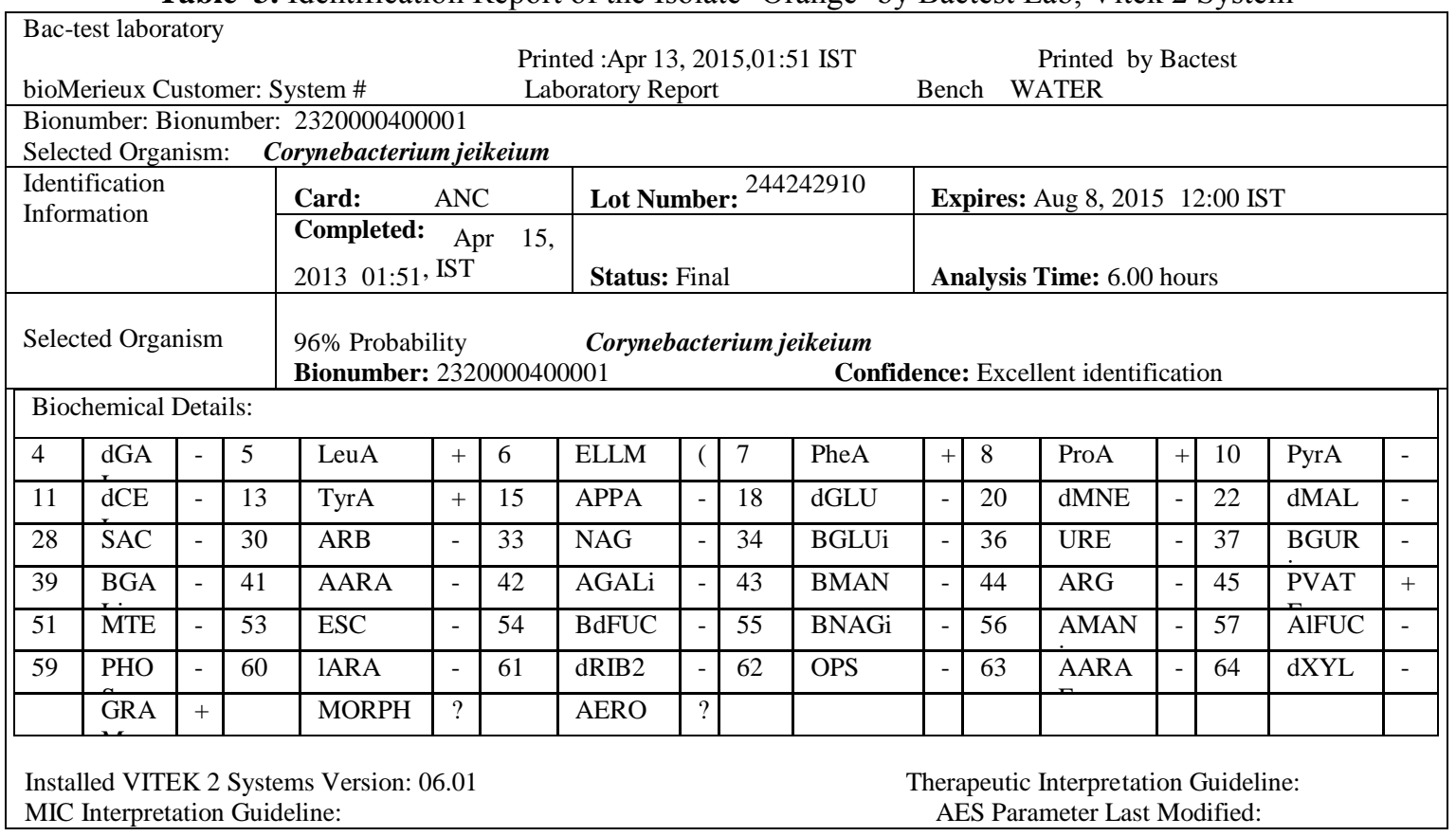

\subsection{Biobleaching of paper-pulp mill effluent}

It was observed that the absorbance was decreased for the consequent days and the colour removal percentage was calculated for each isolate and for the mixed consortium. The colour reduction percent was noticeable as compared to the control on $3^{\text {rd }}$ day as summarized in the Table 4.

Table 4. Percent Biobleaching of Paper-pulp mill Effluent

\begin{tabular}{|l|l|l|l|}
\hline \multirow{2}{*}{ Isolates } & \multicolumn{3}{|c|}{ Biobleaching \% } \\
\cline { 2 - 4 } & $\mathbf{5 0 \%}$ & $\mathbf{7 5 \%}$ & $\mathbf{1 0 0 \%}$ \\
\hline Mixed-Consortium & 91.61 & 89.47 & 86.84 \\
\hline Sphingomonas paucimobilis & 91.32 & 86.57 & 84.21 \\
\hline Corynebactrium jeikeium & 83.82 & 82.43 & 78.94 \\
\hline
\end{tabular}

Different dilutions of the effluent i.e. $50 \%, 75 \%$ and $100 \%$ were decolorized by the isolates as axenic cultures as well as in mixed consortia and the biobleaching and biodegradation of paper and pulp mill effluent measured by U.V. spectrophotometer at $280 \mathrm{~nm}$ were represented graphically as shown in Fig. 2, 3 and 4.

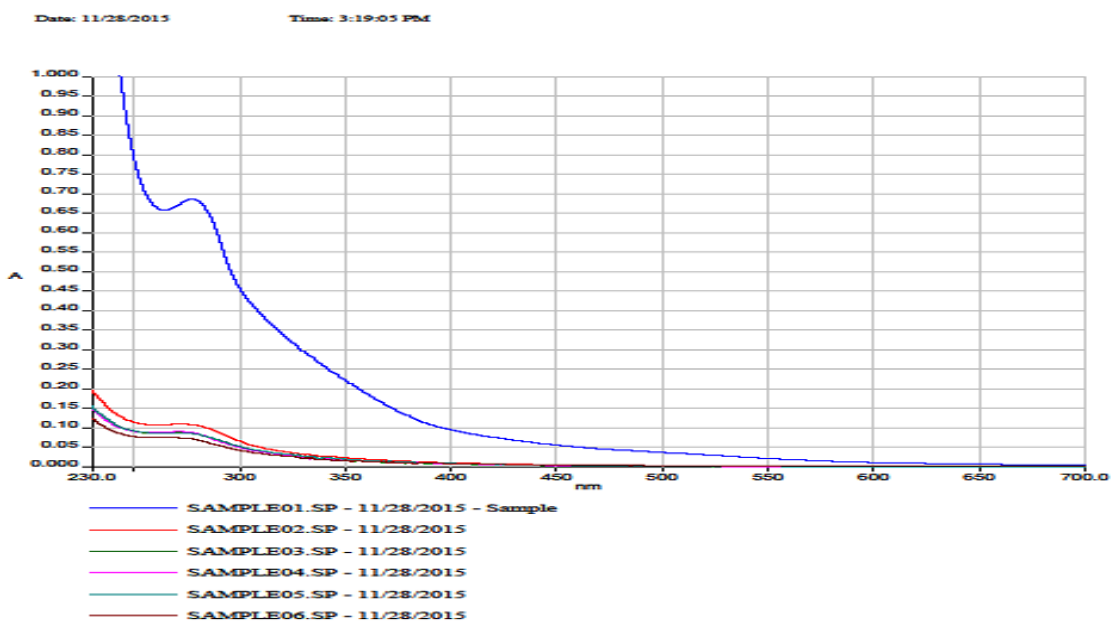

Fig. 2 Biobleaching and biodegradation of $50 \%$ effluent 


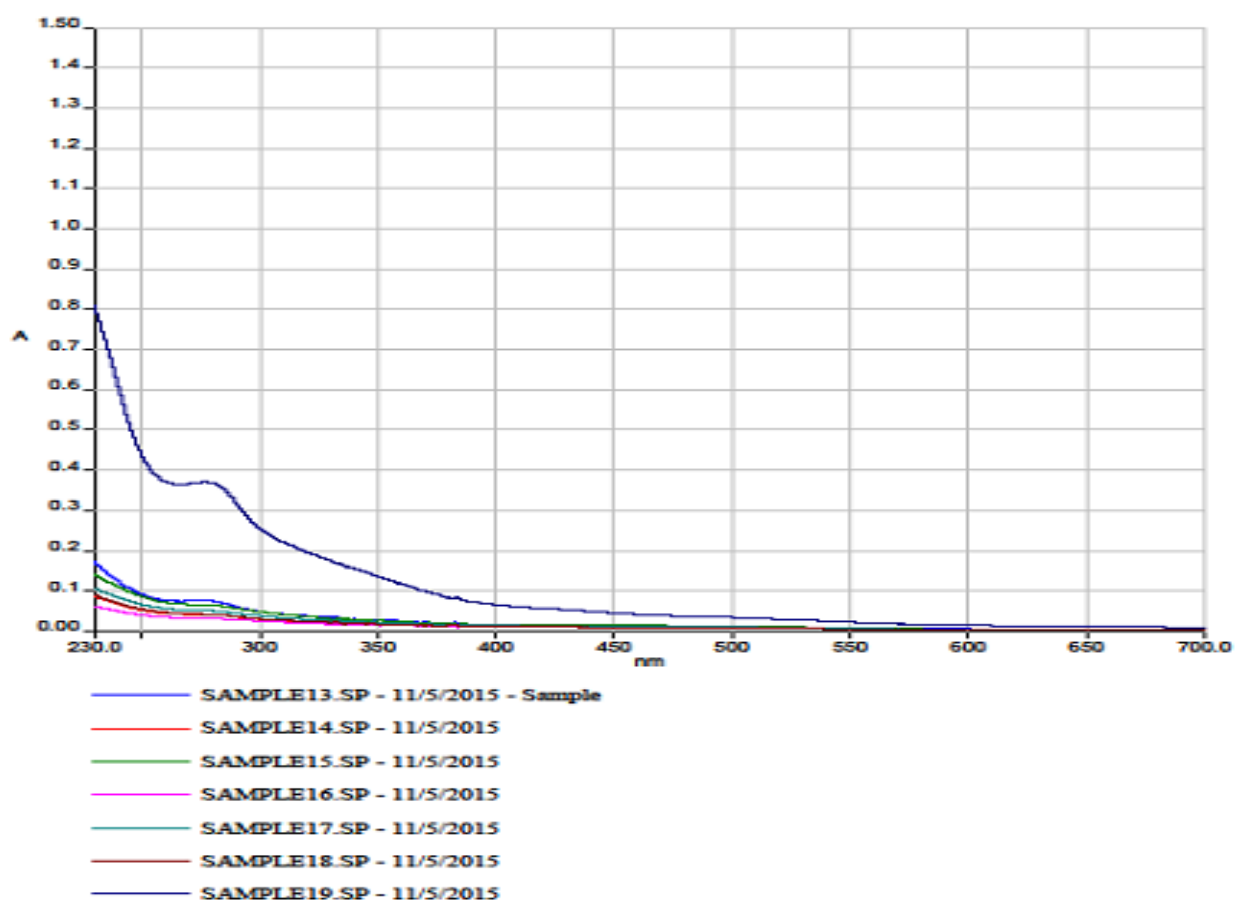

Fig. 3 Biobleaching of $75 \%$ Effluent
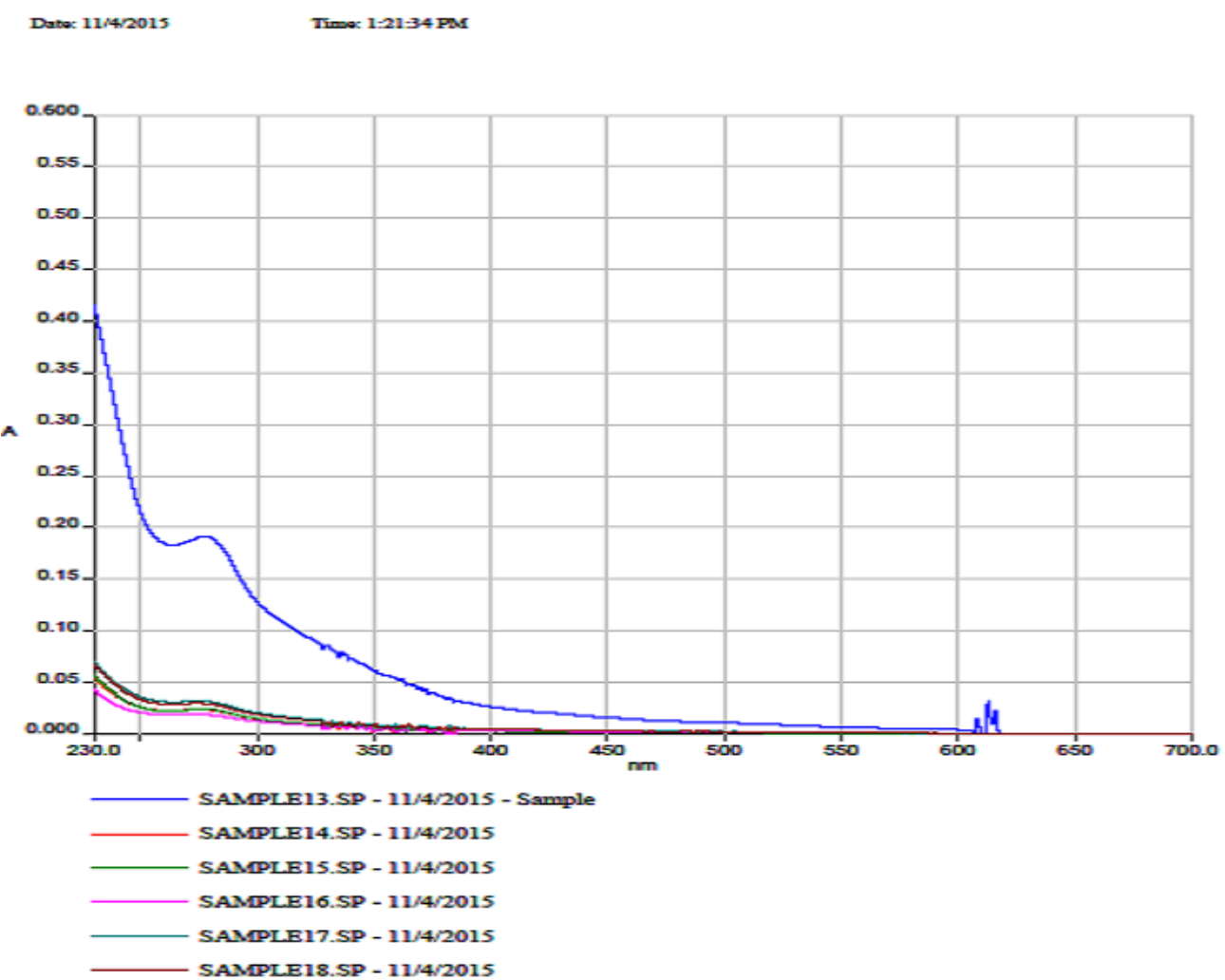

Fig. 4 Biobleaching of 100\% Effluent

\subsection{LiP Assay}

The isolates efficiently decolorized methylene blue substrate and significant lignolytic activity was noticed for the isolates Sphingomonas paucimobilis and Corynebactrium jeikeium i.e. $73.45 \%$ and $69.27 \%$ respectively as shown in Table 5 which was estimated spectrophotometrically. 
Table 5. Percent LiP Activity estimated by MB Assay

\begin{tabular}{|l|l|l|}
\hline Sr. No. & Isolate & \% LiP Activity \\
\hline 1. & Sphingomonas paucimobilis & 73.45 \\
\hline 2. & Corynebactrium jeikeium & 69.27 \\
\hline 3. & Actinomycete species & 67.90 \\
\hline
\end{tabular}

\section{Conclusions}

In the present study, the application of the lignin peroxidase enzyme as a crude extract of the isolateculture broth was reported as an effective biobleaching and biodegradation tool for the treatment of paper-pulp mill effluent which was measured spectrophotometrically. The isolates Sphingomonas paucimobilis (White) and Corynebactrium jeikeium (Orange) were found to be efficient lignin degraders as compared to the others and showed $91.32 \%, 86.57 \%, 84.21 \%$ and $83.82 \%, 82.43 \%, 78.94 \%$ biobleaching when applied as axenic cultures while the mixed consortia being the most effective with biobleaching of $91.61 \%, 89.47 \%$ and $86.84 \%$ of the effluent $50 \%, 75 \%$ and $100 \%$ respectively.

The maximum biobleaching was observed for the effluent concentration of 50\%. Therefore it can be concluded that the dilution of the effluent plays crucial role in the treatment and the possible reason for the effective bleaching of $50 \%$ effluent can be the toxic factors which may be present in the effluent were diluted with subsequent dilution of the effluent and thus making it suitable for luxurious bacterial growth and enhanced enzyme synthesis as compared to the others i.e. $75 \%$ and non-diluted (100\%) effluent concentration. Thus, the application of the isolates Sphingomonas paucimobilis, Corynebactrium jeikeium and their mixed consortium can be an effective tool for the bleaching and biodegradation of paper-pulp mill effluent which can be fast, economical and safe method over the other conventional and hazardous chemical methods .

\section{References}

[1]. Howard R.L., Abotsi E, Jansen van Rensburg E.L. and Howard S., Lignocellulose biotechnology: issues of bioconversion and enzyme production, African Journal of Biotechnology, 2 (12), 2003, pp. 602-619.

[2]. Gomathi, V., Cibichakravarthy,B., Ramanathan, A., Sivaramaiah Nallapeta, Ramanjaneya V., R. Mula and Jayasimha Rayalu D., Decolourization of paper mill effluent by immobilized cells of Phanerochaete chrysosporium., International journal of plant, animal and environmental science., 2 (1), (2012), 141-146.

[3]. Bajpai P. and Bajpai P. K., Biological color removal of pulp and paper mill wastewaters, J. Biotechnology, 33, 211-220, (1994).

[4]. Bholay A. D., Borkhataria Bhavna V. and Jadhav Priyanka U., Bacterial lignin peroxidase: A Tool for Biobleaching and Biodegradation of Industrial Effluents, Universal journal of environmental research and technology, 2 (1), (2012), 58-64.

[5]. Chai Chu Chia, Enhanced Production Of Lignin Peroxidase And Manganese Peroxidase By Phanerochaete Chrysosporium In A Submerged Culture Fermentation And Their Application In Decolourisation Of Dyes; Thesis Submitted In Fulfilment Of The Requirements For The Degree Of Master Of Science January (2008).

[6]. Singh P. and I. S. Thakur, "Removal of Color and Detoxification of Pulp Mill Effluent by Microorganisms in Two Step Bioreactor," Journal of Scientific \& Industrial Research, 63 (11), (2004), pp. 944-948.

[7]. Levin L., Papinutti L. and Forchiassin F., Evaluation of Argentinean White Rot Fungi for their ability to produce lignin-modifying enzymes and decolourize industrial dyes. Bioresour. Technol. 94, (2004), 169-176.

[8]. Abadulla E ${ }^{1}$, Tzanov T, Costa S, Robra K.H., Cavaco-Paulo A, Gübitz GM; Decolorization and detoxification of textile dyes with a laccase from Trametes hirsute, Appl Environ Microbio., 66(8):33, (2000)a, 57-62.

[9]. Palmieri Gianna, Cennamo G., Sannia G., Remazol Brilliant Blue R Decolourisation by the Fungus Pleurotus ostreatus and Its Oxidative Enzymatic System, Enzyme and Microbial Technology, 36, (2005) 17-24.

[10]. Abadulla E., Robra, K.H., Gubitz, G.M., Silva, L.M., Paulo, A.C, Enzymatic decolorization of textile dyeing effulents. Textile Res. J., 70, (2000), $409-414$.

[11]. Ahammed Shamla, Production and Characterization of lignin peroxidases from Mangrove Ascomvcetes, Biochemical Processing Division Regional Research Laboratory (CSIR), (2002), 1-107.

[12]. Allen C.D., Grethien H.E. \& converse,A.Q., "Process studies for Enzymatic hydrolysis using High solids slurries of Acid pretreated Mixed Hardwood," Biotech, bioeng.symp, 13, (1983),99-111.

[13]. Buzzini A. P., M. A. Nolasco, A. M. Springer and E. C. Pires, , "Evaluation of Aerobic and Anaerobic Treatment of Kraft Pulp Mill Effluent for Organochlorines Removal," Water Practice \& Technology, 1( 3), (2006).

[14]. Cullen D. and Kersten, Enzymology and Molecular Biology of Lignin Degradation Straw lignin bio-degradation of Progress: 11:46:00 -28171, (2011), 1-4.

[15]. Dayanand C. Kalyani, Swapnil S. Phugare,Utkarsha U. Shedbalkar, Jyoti P. Jadhav, Purification \& Characterization of a bacterial peroxidase from the isolated strains, Pseudomonas sp. SUK1 \& its application for textile dye decolourization; Annals of Microbiology, September, 61(3), (2011), pp 483-491.

[16]. Duran N. and Esposito E., "Potential applications of oxidative enzymes \& phenoloxidases-like compounds in wastewater \& soli treatment": a review. Application catalysis, 28, (2000), 83-99. 